\title{
Evaluating Osteoporotic Fracture Risk in Latin American Countries
}

\author{
Enrique Lopez Gavilanez ${ }^{1,2^{*}}$, Angel Segale Bajana ${ }^{1,3}$ \\ ${ }^{1}$ AECE Research Group from Association of Clinical Endocrinologists of Ecuador, Guayaquil, Ecuador. \\ ${ }^{2}$ Servicio de Endocrinología, Hospital Docente de la Policía Nacional Guayaquil $N^{\circ} 2$, Guayaquil, Ecuador. \\ ${ }^{3}$ Servicio de Medicina Interna, Hospital Docente de la Policía Nacional Guayaquil $N^{\circ} 2$, Guayaquil, Ecuador.
}

Received: February 19,2019; Accepted:February 22,2019; Published: February 26, 2019

*Corresponding author : Dr. Enrique Lopez Gavilanez, Hospital de la Policía Nacional Guayaquil No.2. Avenida de las Américas S/N y E. Noboa. Zip code:

EC090150. Guayaquil, Ecuador. E-mail: enrique_lopezg57@hotmail.com

\section{Editorial}

The epidemiology of osteoporosis (OP) has been extensively studied especially in countries of the northern hemisphere (USA, Europe), while in Latin America (LA) data is scarce in relation to the North American or European populations [1-5]. Hip fracture (HF), although it is the least frequent $(<20 \%)$ of all osteoporotic fractures, is considered an appropriate model for the epidemiological study of OP, since patients who suffer from it practically always enter a hospital for their attention [6] which allows the epidemiological registration of them. In contrast, patients with humerus or distal radius fractures are usually treated outside the hospital and therefore are underreported. The recording of the rate of clinical vertebral fractures is even more complex because the definitions vary, and it is difficult to distinguish recent painful vertebral fractures from the most common radiological vertebral deformities detected in patients with back pain [6].

Worldwide, the incidence of HF varies from country to country, with the highest figures reported in the countries of the northern hemisphere varying between 250 and 450 per 100,000 inhabitants [6]. In LA, the epidemiology of HF has been studied less, although most countries in the region are considered to be at low risk - with the exception of Argentina - and figures ranging from 50 (Ecuador) [5] to 173 (Mexico) [7] cases per 100000 inhabitants have been described. However, in Ecuador there has been an increase in the incidence of HF in the last 11 years, from 49 per 100,000 in 2005 [5], to 123 per 100,000 in 2016 [8].

The LA countries, as in the rest of the world, are immersed in an epidemiological and demographic transition. Life expectancy at birth in both sexes has increased in recent decades, with this increase being greater in women [9]. In addition, the proportion of older adults, that is, the population with the highest risk of fractures, in LA has also been increasing [9].

This change in the demographics of the population at risk will represent a significant burden on individual morbidity and an enormous expense for the health care systems of the population in the coming decades. Therefore, it was imperative to develop instruments to predict the risk of osteoporotic fractures in all LA countries.
Clinical risk factors (CRFs) have long been recognized as key elements associated with both OP risk as well as fragility fractures. Several studies have focused on identifying the strength of association of selected CRFs such as age, sex, family and personal history of fracture, smoking, alcohol, and physical activity, with fragility fractures. Some of these CRFs have been shown to be independent of BMD and therefore provide additional information in the identification of fracture risk. Several instruments have attempted to identify patients at risk by combining CRFs (OST, osteorisk, ORAI, SCORE).

Among the tools available for fracture risk assessment, the most commonly used is FRAX® [10]. The FRAX model is a computerized algorithm developed in 2008 by the Bone Metabolic Disease Center in Sheffield, UK (http://www.shef.ac.uk/FRAX). FRAX models are currently available for 63 countries, accounting for $79 \%$ of the world's population of 50 years or more [10]. The algorithm, intended for primary care, calculates the probability of fracture from clinical risk factors (CRFs) that are very easy to obtain in men and women. The outcome of the FRAX is the probability at 10 years of suffering a major fracture (MF) (hip, clinical spine, humerus or wrist) and / or an HF. The probability is calculated from age, body mass index (BMI), and dichotomized risk factors that have been extensively described in previous publications [11].

To calculate the risk of specific fractures in each country, it is necessary to know the epidemiology of HF and / or other osteoporotic fractures (MF), as well as mortality data in each country [12]. The available evidence indicates that the incidence of MF can reasonably be predicted from the incidence of HF. Most LA countries incorporated into FRAX have only provided data on the incidence of HF, which required assuming that the agespecific and gender-specific rates of MF found in Malmo, Sweden [13] are comparable to those from countries with incomplete epidemiological information $[14,15]$.

The intervention thresholds (IT) are specific to age and vary in each region and country studied. For example, in US for any MF treatment thresholds $\geq 20 \%$ ( $\geq 3 \%$ in Hip Fractures) are considered, in the UK it is $7.5 \%$ and in Japan $10 \%$. In LA, the following intervention thresholds specific to age and sex were 
recently established. For the ages of 40 and 90 years respectively IT varies from 1.5 to $27.5 \%$ in Argentina, in Brazil 3.8 and $25.2 \%$, in Chile 1.6 and 20.0\%, in Colombia 0, 6 and 10.2\%, in Ecuador 0.9 and 13.6\%, in Mexico 2.6 and 20.0\%, and in Venezuela 0.7 and $22.0 \%$ [16].

In the case of Ecuador, the information on the epidemiology of HF has been recently updated [8], so the its has been recalculated [17] and the updated thresholds with the 2016 Ecuadorian population will be updated soon.

The recent availability of the thresholds for assessment and treatment of OP specific age and gender in 7 countries incorporated into the FRAX tool, are an important advance in the prevention strategy of fragility fractures. Its use by the medical staff of the countries of the region will be of great benefit to populations at risk of LA.

The FRAX instrument can be used at the primary care level to define the actual fracture risk of individual patients in daily practice as an aid in deciding other assessments, referring patients, or to initiate treatment. Its impact may be more important among primary care physicians and specialists with little experience in the detection and treatment of patients at risk of fractures. It should be emphasized that the FRAX model is an evolving tool that is being continuously refined, as the databases of each country are updated with more epidemiological information.

Keywords: FRAX Tool; Osteoporosis; Hip Fracture; Latin America; Osteoporotic Fracture Risk

\section{References}

1. Castro da Rocha FA, Ribeiro AR. Low incidence of hip fractures in an equatorial area. Osteoporos Int 2003;14(6):496-499. Doi: 10.1007/ s00198-003-1394-3

2. Kanis JA, Johnell O, De Laet C, Jonsson B, Oden A, Ogelsby AK . International variations in hip fracture probabilities: implications for risk assessment. J Bone Miner Res 2002;17(7):1237-1244

3. Morales-Torres J. Strategies for the prevention and control of osteoporosis in developing countries. Clin Rheumatol 2007;26(2):139143. Doi: $10.1007 / s 10067-006-0314-2$

4. Morales-Torres J, Gutiérrez-Ureña S; Osteoporosis Committee of PanAmerican League of Associations for Rheumatology. The burden of osteoporosis in Latin America. Osteoporos Int. 2004;15(8):625-632. Doi: $10.1007 / \mathrm{s} 00198-004-1596-3$
5. Orces CH. Epidemiology of hip fractures in Ecuador. Pan Am J Public Health. 2009;25(5):438-442.

6. Kanis JA, Odén A, McCloskey EV, Johansson H, Wahl DA, Cooper C, et al. A systematic review of hip fracture incidence and probability of fracture worldwide. Osteoporos Int. 2012;23(9):2239-2256.

7. Clark P, et al. Osteoporosis in Latin America: panel expert review. Medwave. 2013;13(8):e5791. Doi: 10.5867/medwave.2013.08.5791

8. López Gavilánez E, Chedraui P, Guerrero Franco K, Marriott Blum D, Palacio Riofrío J, Segale Bajaña A. Osteoporotic hip fractures in older adults in Ecuador 2016. Rev Osteoporos Metab Miner 2018;10(2):6370. Doi: $10.4321 /$ s1889-836x2018000200002

9. Estimaciones y proyecciones de población total, urbana y rural, y económicamente activa. América latina. Ecuador. Revisión 2017.

10.Kanis JA, Johansson H, Oden A, Cooper C, McCloskey EV, the Epidemiology and Quality of Life Working Group of IOF. Worldwide uptake of FRAX. Arch Osteoporos. 2014;9:166. Doi: 10.1007/s11657013-0166-8

11.Kanis JA; World Health Organization Scientific Group.(2008) Assessment of osteoporosis at the primary health-care level. Technical report. WHO Collaborating Centre, University of Sheffield, UK.

12. Kanis JA, Harvey NC, Johansson H, Odén A, Leslie WD, McCloskey EV. FRAX and fracture prediction without bone mineral density. Climacteric. 2015;18(2):2-9. Doi: 10.3109/13697137.2015.1092342

13. Kanis JA, Johnell O, Oden A, Sembo I, Redlund-Johnell I, Dawson A, De Laet C, Jonsson B. Long-term risk of osteoporotic fracture in Malmö. Osteoporos Int. 2000;11(8):669-674

14. Jaller-Raad JJ, Jaller-Char JJ, Lechuga-Ortiz JA, Navarro-Lechuga E, Johansson H, Kanis JA. Incidence of hip fracture in Barranquilla, Colombia, and the development of a Colombian FRAX model. Calcif Tissue Int. 2013;93(1):15-22. Doi: 10.1007/s00223-013-9717-7

15.Zerbini CA, Szejnfeld VL, Abergaria BH, McCloskey EV, Johansson H, Kanis JA. Incidence of hip fracture in Brazil and the development of a FRAX model. Arch Osteoporos. 2015;10:224. Doi: 10.1007/s11657015-0224-5

16. Clark P, Denova-Gutiérrez E, Zerbini C, Sanchez A, Messina O, Jaller JJ, Campusano C, Orces CH, Riera G, Johansson H, Kanis JA. FRAX-based intervention and assessment thresholds in seven Latin American countries. Osteoporos Int. 2018;29(3):707-715. Doi: 10.1007/ s00198-017-4341-4

17. Lopez Gavilanez E, Gavilanes AWD, Chedraui P, Segale Bajaña A. New FRAX-based intervention and assessment thresholds for the Ecuadorian population. Arch Osteoporos. 2018;13(1):102. Doi: 10.1007/s11657-018-0521-x 